\title{
A pancreas tumor derived organoid study: from drug screen to precision medicine
}

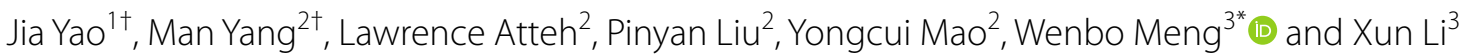

\begin{abstract}
Pancreatic ductal adenocarcinoma (PDAC) one of the deadliest malignant tumor. Despite considerable progress in pancreatic cancer treatment in the past 10 years, PDAC mortality has shown no appreciable change, and systemic therapies for PDAC generally lack efficacy. Thus, developing biomarkers for treatment guidance is urgently required. This review focuses on pancreatic tumor organoids (PTOs), which can mimic the characteristics of the original tumor in vitro. As a powerful tool with several applications, PTOs represent a new strategy for targeted therapy in pancreatic cancer and contribute to the advancement of the field of personalized medicine.
\end{abstract}

Keywords: Pancreas cancer, Pancreatic ductal adenocarcinoma (PDAC), Pancreas tumor derived organoids (PTOs), Drug screen, Precision medicine

\section{Introduction}

Pancreatic ductal adenocarcinoma (PDAC), an exocrine pancreatic malignancy, is a rapidly developing and fatal disease that accounts for the majority of pancreatic cancers. It is the 8th and 9th deadliest malignancy in males and females globally, respectively [1]. Although PDAC treatments, particularly immunotherapy and adjuvant chemotherapy, have been optimized, 5-year survival in patients with PDAC remains low at 7-8\% [2]. There are multiple factors responsible for such suboptimal results, e.g., late diagnosis, quick progression featuring metastasis, and resistance to currently available chemotherapeutics. Unfortunately, the majority of patients are diagnosed at later phases after metastasis is involved, and such individuals have already been affected for 6-12 months prior to diagnosis. Accordingly, gaining insights into the mechanisms of disease initiation and progression is of vital importance for early detection and risk stratification, and

\footnotetext{
*Correspondence: mengwb@lzu.edu.cn

†Jia Yao and Man Yang contributed equally to this article

${ }^{3}$ Department of General Surgery, The First Hospital of Lanzhou University,

The First Clinical Medical School of Lanzhou University, Lanzhou 730000, Gansu, China

Full list of author information is available at the end of the article
}

could aid in developing targeted therapeutic strategies $[3,4]$. Despite the progress made with respect to insights into the mechanisms of PDAC pathogenesis, the actual impact in terms of benefits to patients remains unclear $[5,6]$. Thus, novel model systems have been proposed and adopted to address the abovementioned issue with the hope that data could be translated into optimized diagnostics and therapeutics [7]. The present study highlights a patient-derived pancreatic tumor-derived organoid (PTO), which could combine drug and genomic/ proteomic screening in vitro, thus raising the hope of precision therapy for pancreatic cancer $[8,9]$.

\section{Pancreatic tumor organoid culture system 3D cell culture model}

The 3D cell culture model is a method avoiding cell attachment to the plate by growing suspension or matrixembedded cells. The first attempts to develop cancerous pancreatic cells spheroids have failed owing to limited cell viability and longevity [10]. Spheroids that are excessively small result in the loss of cells due to the shear stress on cells in low adhesion cultures. Spheroids that are big will affect the diffusion of oxygen and metabolism of substances in cells within spheroids, resulting in the inconsistent differentiation of the whole spheroid [11]. original author(s) and the source, provide a link to the Creative Commons licence, and indicate if changes were made. The images or other third party material in this article are included in the article's Creative Commons licence, unless indicated otherwise in a credit line to the material. If material is not included in the article's Creative Commons licence and your intended use is not permitted by statutory regulation or exceeds the permitted use, you will need to obtain permission directly from the copyright holder. To view a copy of this licence, visit http://creativecommons.org/licenses/by/4.0/. The Creative Commons Public Domain Dedication waiver (http://creativeco mmons.org/publicdomain/zero/1.0/) applies to the data made available in this article, unless otherwise stated in a credit line to the data. 
However, recently, 3D cultures of murine and human pancreatic cells have been successfully established in multiple laboratories using special matrices that help maintain interactions among cells and between cells and the matrix, promoting spheroid structures $[12,13]$.

Pancreatic spheres, which could be created from pancreatic ductal and acinar cells, are likely to simulate some PDAC features in vivo, including microenvironmental parameters and drug response [14-16]. 3D spheres based on embryonic pancreatic cells partly reflect pancreas development, and express PDX1 and SOX9 $[17,18]$. Ductal cell-derived spheres have been utilized for evaluating pancreatic carcinogenesis, notably the function of KRAS mutation and in drug assessment [19-22].

The initial complete protocol for directly purifying ductal epithelial cells from the mouse pancreas as well as duct-like cells, which does not require further culture steps for 3D culture, was reported in 2013 [23]. This technique utilizes Dolichos biflorus agglutinin (DBA) in magnetic bead purification. Ductal cells could be grown on and inside a collagen matrix for 2D and 3D cultures, respectively [24]. Notably, the above method could be applied in several pathological states, such as inflammation and cancer, and physiological processes, such as embryonic development [25].

\section{Organoid culture model}

3D-culture spheres have inspired a novel ex vivo model called "tumor organoids". This involves cells cultured in a 3D structure directly from primary tissue specimens or cancer cell lines capable of self-renewal and selforganization, with appearance and functional properties comparable to those of the source tissue [26-28]. Tumor organoids could be indefinitely passaged with preserved genetic properties, like cell epigenetic markers, functional characteristics, etc. They also share numerous features with 3D spheres. However, 3D cultures are obtained from monolayer cells, while tumor organoids are generated from tissue specimens in 3D cultures using the same protocol described previously by our group [29].

Briefly, tumor organoids are formed by digesting (enzymatically or mechanically) original tumor tissues, which undergo embedding in a matrix (collagen or Matrigel) [30]. Additionally, particular growth factors and differentiation regulators, including epidermal growth factor (EGF), fibroblast growth factor 10, Rspo1 (Wnt pathway inducer), Noggin (BMP pathway suppressor), Wnt3a, nicotinamide, $\mathrm{N}$-acetylcysteine, gastrin, and A83-01 (Alk suppressor), are needed to supply mesenchymalbased signals [31]. Furthermore, normal (untransformed) human tumor organoids developed from ductal cells or tumor tissue samples require supplementation with prostaglandin E2. Flow cytometry and magnetic beads (with linked DBA) are optimal for isolating ductal cells, although non-ductal cells have been shown to be not feasible and are thus eliminated after one passage [32, 33].

The tumor organoid culture system for pancreatic tissues was first described in 2013 [34]. Subsequently, an organoid model derived from mouse and human adenocarcinoma of the pancreas has been successfully established by embedding cells in Matrigel [26]. Researchers have used serum-free media supplemented with multiple growth factors for propagating mouse adult pancreatic duct cells. Such media activate Wnt signaling, expanding ductal structures in serum-free conditions, further upregulating Lgr5 (stem cell biomarker and RSPO1 receptor) and promoting self-renewal [34]. Additional vital constituents of these media include Glutamax, HEPES, Noggin, Gastrin I, nicotinamide, EGF, fibroblast growth factor 10, $N$-acetylcysteine, and B27 supplement, and in human specimens, Wnt3a and Primocin [35]. Remarkably, the tumor organoids generated are physiologically similar to the original pancreatic tumor tissues. In addition, they have ductal epithelial cell biomarkers but no genes reflecting acinar and endocrine lineages. After tumor organoids were orthotopically transplanted into immunodeficient mouse models, pre-invasive tumors likening preneoplastic lesions (PanIN) that progressed to invasive adenocarcinoma and metastasize were detected. Therefore, this represents an attractive model for cancer progression.

Furthermore, murine PTOs have been subjected to gene expression analysis (RNAseq) and proteomics (mass spectrometry), revealing gene and proteomic profiles are related to pancreatic cancer progression. In another method, fibroblasts and tumor cells could be propagated in Matrigel and complete medium (1:2). The latter medium contained $10 \%$ fetal bovine serum, $1 \%$ penicillin and streptomycin cocktail, and $10 \mathrm{ng} / \mathrm{mL}$ EGF receptor. Such conditions facilitate the generation of tumor cells with fibroblasts from human and mouse PDAC $[25,30]$.

A method exploiting an air-liquid interface that encompasses inner collagen gel-packed cells directly exposed to air (cells in contact with elevated oxygen amounts) has been developed [37]. This technique utilizes a matrix containing collagen I in lieu of Matrigel [38] and allows 3D organoid culture from newborn or adult mouse tissue samples without exogenously supplementing growth factors.

Another strategy to develop PTOs from pancreatic cancer cell lines, included endothelial or mesenchymal cells, involves the self-assembly process [39-41]. Cancerassociated fibroblasts participate in extracellular matrix (ECM) production and contribute to tumor growth and resistance to chemotherapeutics. Lately, a research group developed a co-culture model of pancreatic cancer 
organoids and stellate cells $[31,36]$. This model yielded increased proliferation degree ofpancreatic cancer cells [42]. Furthermore, the authors reported that cancerrelated fibroblasts were heterogeneous, expressing a range of levels of smooth muscle actin and interleukin (IL) -6 based on their proximity to the organoids. The above findings indicate that ECM played a important role in pancreatic cancer cells proliferation and differentiation $[13,43]$.

Despite the easy access to cell/tissue resources for PTOs establishment, the interactions among different cell types and between the cells and the stroma remain unclear. PTOs can be generated not only by excising tissues or biopsy, but also from endoscopy-mediated fine-needle aspiration or biopsy specimens. Moreover, they could be produced from small tissue quantities [44-46]. Lastly, PTOs retain the genetic phenotypes and biological features of the original tissue. In addition, researchers also found that PTOs could be generated from iPSCs with Kras/tps3 modification [22]. The primary culture model of PTOs is depicted in Fig. 1. Well-established PTO culture systems are summarized in Table 1.

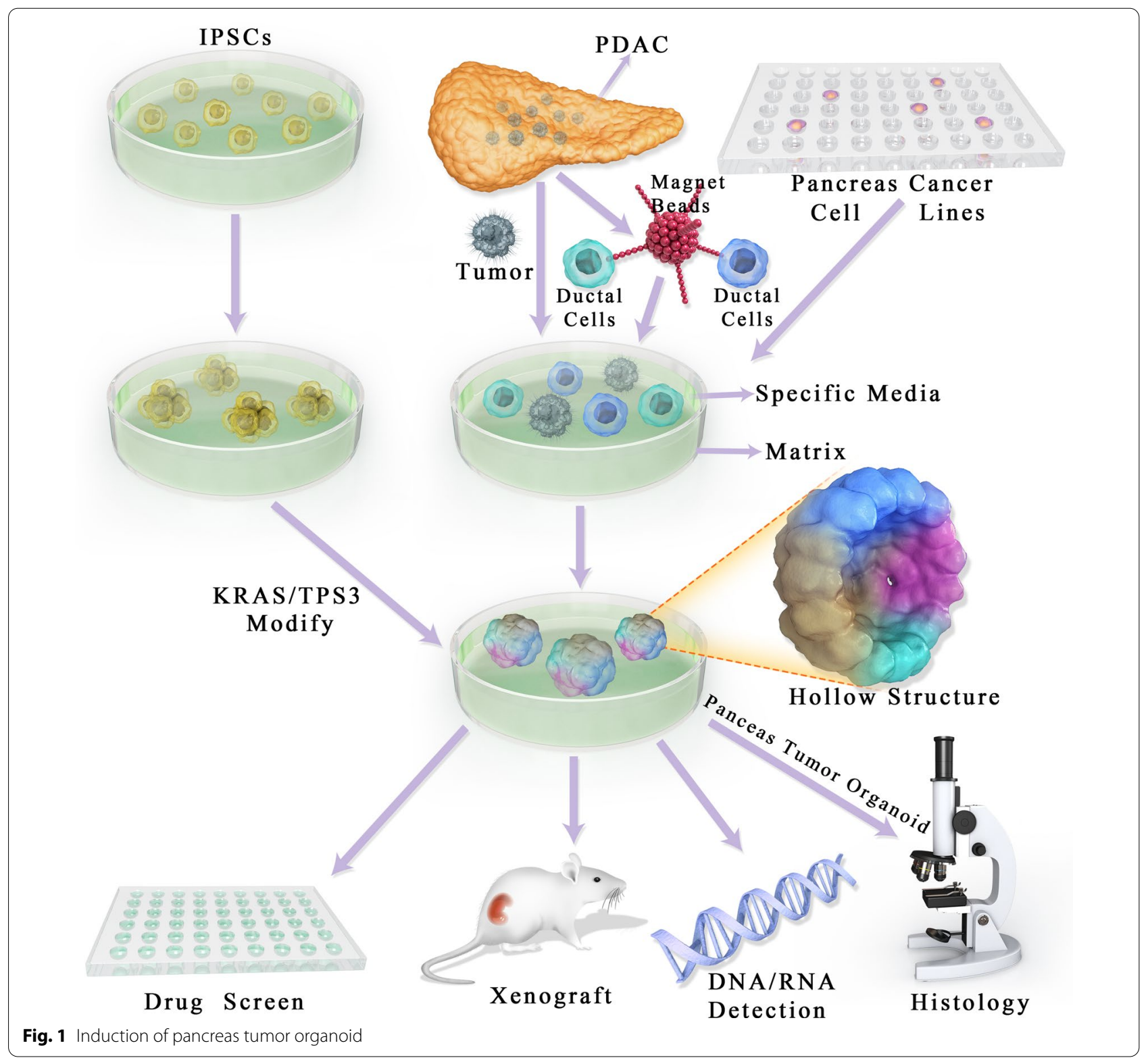


Table 1 Pancreas tumor organoids culture system established for drug and biomarker screen

\begin{tabular}{|c|c|c|c|c|c|c|}
\hline Tissue & Species & Matrix & Trans-plantation & Drug testing & $\begin{array}{l}\text { Biomarker } \\
\text { screen }\end{array}$ & References \\
\hline $\begin{array}{l}\text { Nomal pancreas } \\
\text { PanIN } \\
\text { PDAC }\end{array}$ & $\begin{array}{l}\text { Murine } \\
\text { Human }\end{array}$ & Embedded in Matrigel & $\begin{array}{l}\text { Generation of PDAC and } \\
\text { PanIN }\end{array}$ & Yes & Yes & $\begin{array}{l}{[9]} \\
{[24]} \\
{[27,28]} \\
{[30]}\end{array}$ \\
\hline $\begin{array}{l}\text { iPSCs } \\
\text { PDAC }\end{array}$ & Human & Media and Matrigel & Generation primary tumor & Yes & Yes & [25] \\
\hline PDAC & $\begin{array}{l}\text { Murine } \\
\text { Human }\end{array}$ & Media and Matrigel & - & Yes & Yes & $\begin{array}{l}{[34]} \\
{[89]}\end{array}$ \\
\hline $\begin{array}{l}\text { Neonatal tissue } \\
\text { PDAC } \\
\text { iPSCs }\end{array}$ & $\begin{array}{l}\text { Murine } \\
\text { Human }\end{array}$ & Air-liquid interface on Matrigel & Generation of PDAC & Yes & Yes & [32] \\
\hline
\end{tabular}

PanIN pancreas intraepithelial neoplasia, PDAC pancreas ductal adenocarcinoma, iPSCs induced pluripotent stem cells

\section{Applications of PTOs}

PTOs are an effective research tool that can be utilized in numerous major areas of pancreatic tissue pathology [47]. PTOs can be obtained quickly and do not require large tissue amounts, thus enabling for drug development and the assessment of biomarkers for diagnosis. Various disease phases and clinical scenarios could also be mimicked by such a tool. Large genotranscriptomic trials of human pancreatic malignancies have assessed surgical samples. However, only $20 \%$ of pancreatic cancer cases are eligible for surgical resection, with the remaining 80\% showing advanced disease and poor prognosis [48-51]. The aforementioned shortcomings can be potentially resolved using the PTO platform [52, 53] (Fig. 2).

\section{Neoplasia modeling}

PTOs allow the modeling of human pancreatic cancer development in vitro [47] and thus represent an excellent approach for studying pancreatic cancer progression. Because PTOs can routinely be obtained from normal human epithelia, mutational processes during different phases of malignancy can be monitored in vitro, and in vitro culture of a range of premalignant pancreas neoplasias is now feasible [27]. However, PTOs do not rely on the R-spondin protein to activate Wnt pathway mutations, and their dependence on other niche growth factors is specifically lost in the adenomato-carcinoma transition [32, 45, 54]. Another relevant application of PTOs is their use in xenografts $[55,56]$. Upon PTO transplantation into immunodeficient mice, PanINs capable of developing invasive adenocarcinoma and metastasis are generated, thereby representing an efficient and convenient option for studying tumor progression and identifying novel biomarkers in the initial phases of PDAC [57-59].

\section{Biomarker identification}

For identifying biomarkers and stratifying patients according to genetic profile and therapeutic response, biobanks of 3D organoids attract increasing attention. Organoid biobanks produced from tissues specimens collected perioperatively or by endoscopic ultrasound biopsy allow the sampling of a broad range of tumors of various stages [39, 48, 60-65]. Interestingly, PTOs generated from frozen tumor tissues exhibit comparable morphology, viability, and metabolism to those derived from fresh tissues [66]. These findings indicate that pancreatic cancer-specific and early-phase biomarkers can be feasibly identified $[30,67]$. mRNA expression analysis of human pancreas organoid reveals that hPOs express increased levels of the adult stem cell marker LGR5. Organoid developed from isolated ducts and islets all express similar levels of the pancreatic progenitor and beta-cell marker PDX1 [68]. It was also reported that ducts-derived organoid express higher levels of ductal marker SOX9 in comparison to islets. These findings suggest pancreas organoid maintain a pancreatic ductal identity during in vitro culture [57].

\section{Genomic studies}

PTOs constitute a new tool for analyzing gene expression in tumor cells, with high selectivity $[69,70]$. They could be utilized for validating genetic alterations involved in cancer progression and identifying genes related to different phases of tumor progression, therapeutic response, and prognosis [54, 60, 62, 63, 71-73]. For instance, an organoid model system was used for evaluating NRF2's role in PDAC progression and knocking down its transcription factor in human and mouse organoids [74]. The authors revealed low proliferation in human tumor-like organoids not expressing NRF2. In addition, these authors demonstrated 


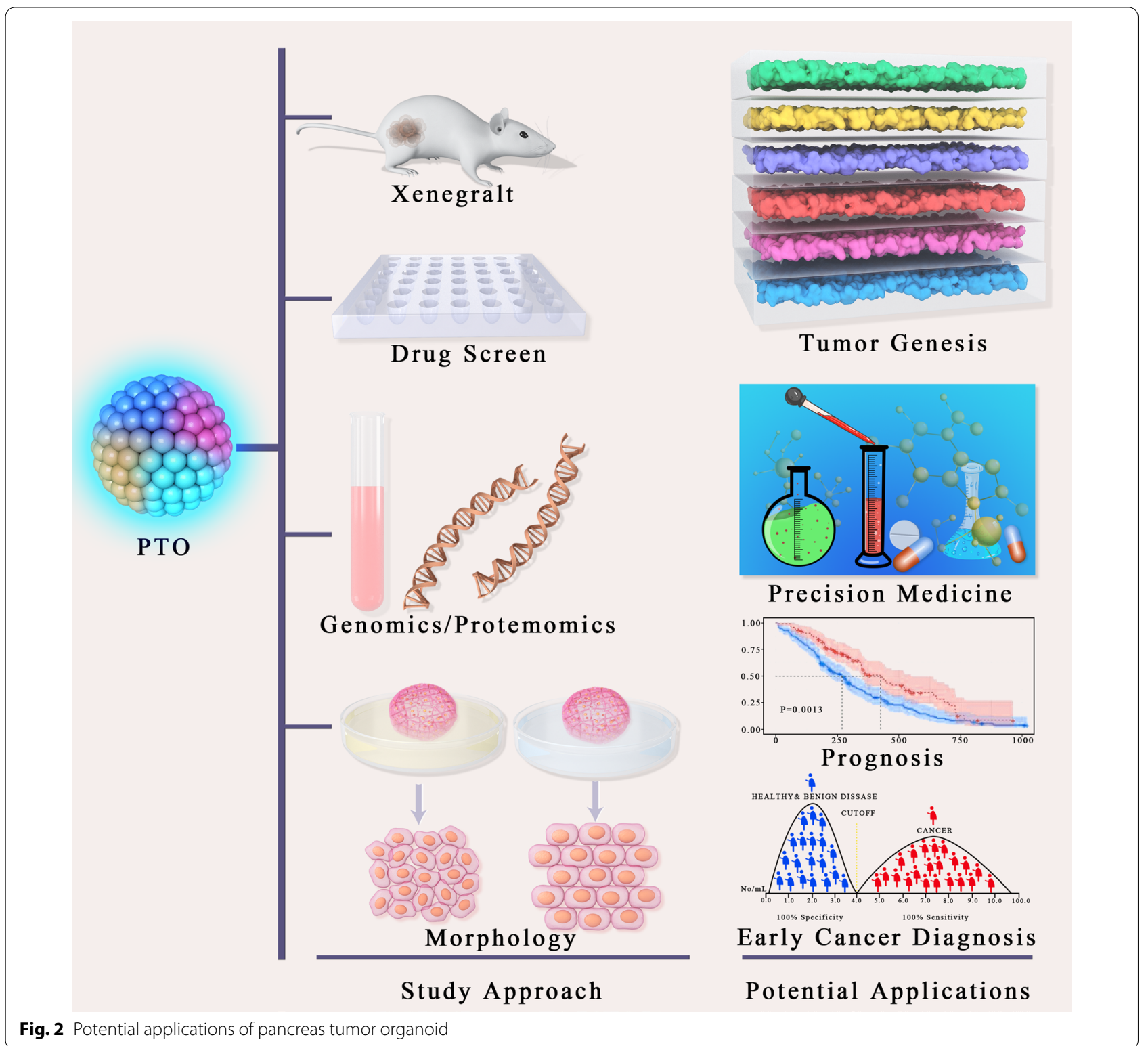

an association between NRF2 and mRNA translation through REDOX regulation [36, 51, 67, 75-89].

PTOs is not retained well when assessing structural variation events, but there are striking cases of clustering of SV events across particular chromosomes that are retained when tumors are implanted into their respective disease models [13]. Comparison of tumors, PDXs, and PTOs revealed that several genetic aberrations are sample-specific, PDXs and PDOs may serve as tractable and transplantable systems for probing the molecular properties of PDAC [90].

\section{Tumor organoid biobanks}

Most specimens assessed by cancer consortia, including the International Cancer Genome Consortium and The Cancer Genome Atlas, are perioperatively obtained samples of primary tumors, while metastatic tumors usually reflect the lethal phase of cancer. In theory, PTOs enable the expansion of limited tumor specimens, thereby allowing the assessment of malignant cells at all stages [61]. PTO biobanks broaden the patient sample types that can be studied in the laboratory. Biobank research has primarily verified that PTOs have the features of respective 
primary tumors, at least according to the data obtained from bulk DNA sequencing. Nevertheless, whether intratumoral heterogeneity is observed in organoid cultures remains unclear [29]. An additional unstudied issue is the clonal drift of "bulk" organoids in cultures maintained for extended periods.

Several initiatives have been implemented to increase the availability of well-characterized PTO biobanks in the academia and industry. The nonprofit HUB (www.hub4o rganoids.eu) provides established organoid biobanks. The Human Cancer Models Initiative (https://ocg.cancer. gov/programs/HCMI) represents a collaborative international consortium building cancer-derived culture models matched to genomic findings and patient features [91]. The HCMI's objective is to improve the availability of the built models and relevant information as a community resource $[53,61]$. Compounded with the technical issues of banking living materials, ethical problems and informed consent challenges associated with such biobanks are complicated.

\section{From drug screening to precision medicine}

PTOs constitute a tool for rapid drug assessment of individual tumors before or in parallel to implementing treatment in patients with PDAC $[92,93]$. Although a one-week time period between biopsy and drug selection has been reported, more recent studies have suggested that extensive drug screening should be performed within 3-4 weeks post-biopsy [45, 60, 94]. This technique can potentially reveal individual treatment vulnerabilities according to the genetic mutation profile and therapeutic response in organoids or determine the next lines of therapy in case of ineffective first-line treatment $[95,96]$. It is also noteworthy that tumors derived from $\mathrm{KPC}$ and $\mathrm{KC}$ mouse models are heavily used for organoid development and drug screening, which provided a proven platform for drug screen for pre-clinical research $[31,97]$.

Additionally, drug screening could be examined in combination with dynamic live imaging for obtaining functional optical metabolic findings $[45,63,94$, 98-102] (Fig. 3). The above multiphoton microscopy method could help in detecting cell metabolism alterations by measuring auto-fluorescence intensity as well as the half-lives of reduced nicotinamide (NAD) and flavin (FAD) adenine dinucleotides. In addition, it can detect heterogeneity, identify nonresponsive subclones, and differentiate between pre-malignant and invasive lesions $[103,104]$. Optical metabolic imaging is highly sensitive in revealing metabolic alterations 1-2 $\mathrm{h}$ following treatment with effective drugs, and such changes correlate with the expected response (i.e., HER2 expression in breast cancer) [105]. Further, optical metabolic imaging distinguishes cell types and drug response [18, 29, 41, 62, 63, 106, 107]. For instance, fibroblasts from PDAC organoids show drug response, despite no overt cell death enhancement [94]. Thus, this method could be adopted to evaluate the response of PDAC patients to stroma-targeting therapies in tumor organoids [23, 108-110].

Owing to the poor prognosis of individuals with metastatic pancreatic cancer, precision therapy for pancreatic cancer remains challenging [82]. In several cases, PTO pharmacotyping was completed in less than 4 weeks, demonstrating the potential of PTOs to determine the best treatment in a clinically meaningful time period in early and late stages of pancreatic cancer [111]. Because complementary genomic and transcriptome analysis is feasible in patients with advanced pancreatic cancer, PTO drug typing and transcriptome characteristics can be prospectively validated, even when first-line therapy is applied [30, 52, 85].

However, this methodology is not uniformly successful in all PDAC patients [53]. Chemosensitivity profiles might stratify and thus ameliorate the initial patient care in pancreatic cancer. Moreover, in combination with longitudinal PTOs' molecular and pharmacologic assessments, such techniques could be modified for optimizing individual patient care [63] (Fig. 4).

\section{Challenge and future directions}

Although PTO systems and their potential applications have attracted increasing attention, their high cost and time-consuming nature cannot be overlooked. In addition, PTOs lack numerous constituents, including fibroblasts, and endothelial, immune and neural cells [39], which result in PTOs developing is the loss of vascularity and immune cell proportion during PTOs subculture. To address these limitations, studies focused on co-culture of organoids with other cell types for generating a more "physiological" microenvironment and identifying putative cell-cell interactions are underway [48].

Although the application of PTOs in pancreatic cancer is at its early stage, many studies have demonstrated several advantages, including the ease of drug testing, the predictive value on PDAC's early diagnosis, and the stability of features shared with the original tumor. Ongoing clinical studies are evaluating the potential utilization of PTOs as a platform for pre- and post-therapy. Standardizing protocols for PTO production is also required for reproducibility. Ideally, optimization should encompass the expansion of PTO development techniques to other pancreatic lesion types, including pancreatic cystic lesions (mucinous cystic and intra-papillary mucinous neoplasms) and neuroendocrine lesions. Moreover, cheaper culture materials must be identified. 

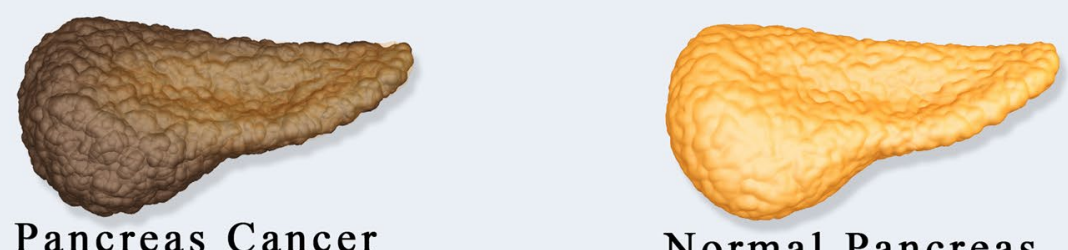

Pancreas Cancer

Normal Pancreas
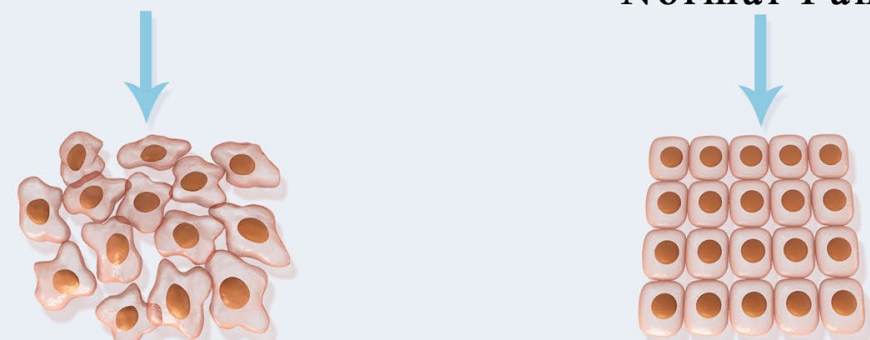

Tumor

Normal
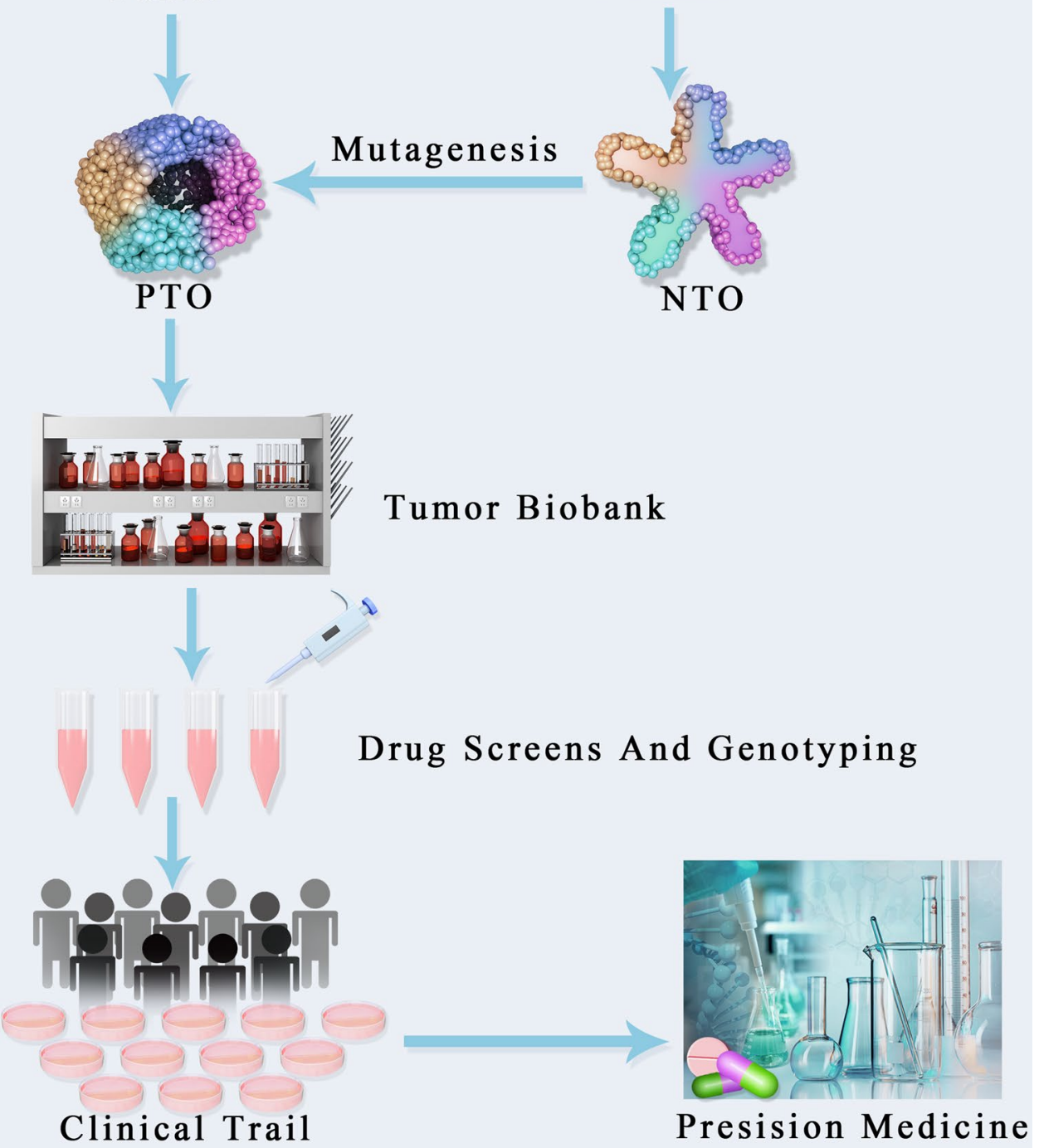

Fig. 3 Presicion medicine based on pancreas organoid technology 


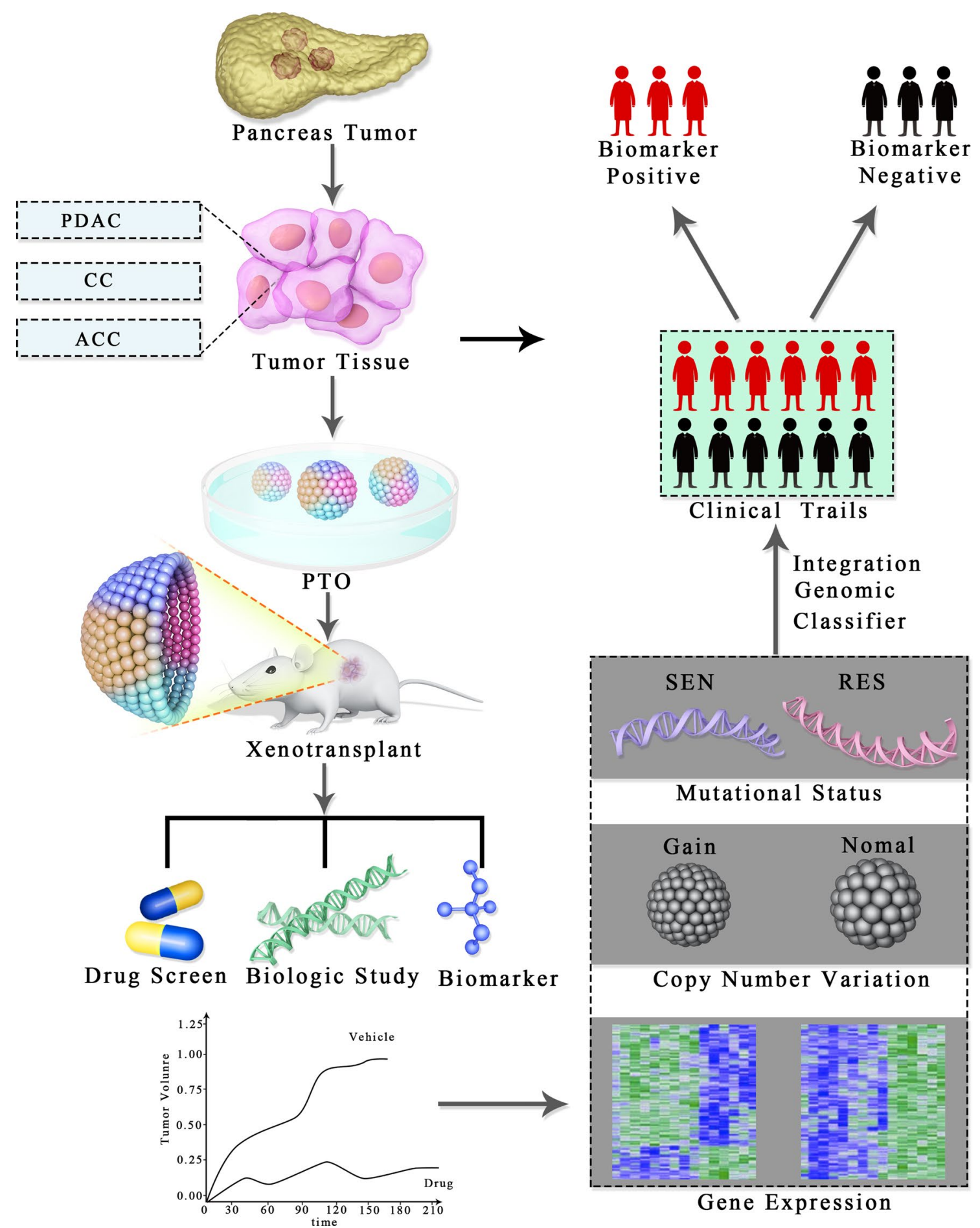

Fig. 4 Pancreas tumor organoid xenotransplant-from surgery to clinical trails

\section{Conclusion}

Various animal models of PDAC have been established, with each approach contributing to the assessment of PDAC's pathogenetic mechanisms. Overall, PTOs constitute a promising and effective tool for tumor targeted therapy, and could contribute to the application of precision medicine in pancreatic cancer. 


\section{Acknowledgements}

Funding grants from the National Natural Science Foundation of China and the Key Research Development Programs of the Provincial Science and Technology Research Projects of Gansu Province are gratefully acknowledged.

\section{Authors' contributions}

$J Y$ and MY wrote the paper. WM and XL modified the manuscript and supervised the project. All authors read and approved the final manuscript.

\section{Funding}

This work was supported by Grant(s) from the National Natural Science Foundation of China (82060551 to Wenbo Meng), and the Key Research Development Programs of the Provincial Science and Technology Research Projects of Gansu Province (18YF1FA109 to Jia Yao).

\section{Availability of data and materials}

Not applicable.

\section{Declarations}

Ethics approval and consent to participate

Not applicable.

\section{Consent for publication}

Not applicable.

\section{Competing interests}

All authors do not have any possible conflicts of interest.

\section{Author details}

${ }^{1}$ Key Laboratory of Biological Therapy and Regenerative Medicine Transformation of Gansu Province, The First Hospital of Lanzhou University, Lanzhou, Gansu, China. ${ }^{2}$ The First Clinical Medical College of Lanzhou University, Lanzhou, Gansu, China. ${ }^{3}$ Department of General Surgery, The First Hospital of Lanzhou University, The First Clinical Medical School of Lanzhou University, Lanzhou 730000, Gansu, China.

Received: 13 February 2021 Accepted: 24 June 2021

Published online: 27 July 2021

\section{References}

1. Siegel RL, Miller KD, Fuchs HE, Jemal A. Cancer statistics, 2021. CA Cancer J Clin. 2021;71(1):7-33.

2. Rahib L, Smith BD, Aizenberg R, Rosenzweig AB, Fleshman JM, Matrisian LM. Projecting cancer incidence and deaths to 2030: the unexpected burden of thyroid, liver, and pancreas cancers in the United States. Cancer Res. 2014;74(11):2913-21.

3. Esposito I, Konukiewitz B, Schlitter AM, Kloppel G. Pathology of pancreatic ductal adenocarcinoma: facts, challenges and future developments. World J Gastroenterol. 2014;20(38):13833-41.

4. Cicenas J, Kvederaviciute K, Meskinyte I, Meskinyte-Kausiliene E, Skeberdyte A, Cicenas J. KRAS, TP53, CDKN2A, SMAD4, BRCA1, and BRCA2 mutations in pancreatic cancer. Cancers (Basel). 2017;9(5):42.

5. Chandana S, Babiker HM, Mahadevan D. Therapeutic trends in pancreatic ductal adenocarcinoma (PDAC). Expert Opin Investig Drugs. 2019;28(2):161-77.

6. Rishi A, Goggins M, Wood LD, Hruban RH. Pathological and molecular evaluation of pancreatic neoplasms. Semin Oncol. 2015;42(1):28-39.

7. Hiroshima Y, Zhang Y, Murakami T, Maawy A, Miwa S, Yamamoto M, Yano S, Sato S, Momiyama M, Mori R, et al. Efficacy of tumor-targeting Salmonella typhimurium A1-R in combination with anti-angiogenesis therapy on a pancreatic cancer patient-derived orthotopic xenograft (PDOX) and cell line mouse models. Oncotarget. 2014;5(23):12346-57.

8. Tiriac H, Belleau P, Engle DD, Plenker D, Deschenes A, Somerville TDD, Froeling FEM, Burkhart RA, Denroche RE, Jang GH, et al. Organoid profiling identifies common responders to chemotherapy in pancreatic cancer. Cancer Discov. 2018;8(9):1112-29.
9. Chen H, Zhuo Q, Ye Z, Xu X, Ji S. Organoid model: a new hope for pancreatic cancer treatment? Biochim Biophys Acta Rev Cancer. 2021;1875(1):188466.

10. Marciniak A, Selck C, Friedrich B, Speier S. Mouse pancreas tissue slice culture facilitates long-term studies of exocrine and endocrine cell physiology in situ. PLOS ONE. 2013;8(11):e78706.

11. Candiello J, Grandhi TSP, Goh SK, Vaidya V, Lemmon-Kishi M, Eliato KR, Ros R, Kumta PN, Rege K, Banerjee I. 3D heterogeneous islet organoid generation from human embryonic stem cells using a novel engineered hydrogel platform. Biomaterials. 2018;177:27-39.

12. Matsuda Y, Ishiwata T, Kawamoto Y, Kawahara K, Peng WX, Yamamoto T, Naito Z. Morphological and cytoskeletal changes of pancreatic cancer cells in three-dimensional spheroidal culture. Med Mol Morphol. 2010;43(4):211-7.

13. Nelson SR, Zhang C, Roche S, O'Neill F, Swan N, Luo Y, Larkin A, Crown J, Walsh N. Modelling of pancreatic cancer biology: transcriptomic signature for 3D PDX-derived organoids and primary cell line organoid development. Sci Rep. 2020;10(1):2778.

14. Longati P, Jia X, Eimer J, Wagman A, Witt MR, Rehnmark S, Verbeke C, Toftgard R, Lohr M, Heuchel RL. 3D pancreatic carcinoma spheroids induce a matrix-rich, chemoresistant phenotype offering a better model for drug testing. BMC Cancer. 2013;13:95.

15. Baker BM, Chen CS. Deconstructing the third dimension: how 3D culture microenvironments alter cellular cues. J Cell Sci. 2012;125(Pt 13):3015-24.

16. Friedrich J, Seidel C, Ebner R, Kunz-Schughart LA. Spheroid-based drug screen: considerations and practical approach. Nat Protoc 2009;4(3):309-24

17. Wartenberg $M$, Ling FC, Muschen $M$, Klein F, Acker $H$, Gassmann $M$, Petrat K, Putz V, Hescheler J, Sauer H. Regulation of the multidrug resistance transporter P-glycoprotein in multicellular tumor spheroids by hypoxia-inducible factor (HIF-1) and reactive oxygen species. FASEB J. 2003;17(3):503-5.

18. Choi SI, Jeon AR, Kim MK, Lee YS, Im JE, Koh JW, Han SS, Kong SY, Yoon KA, Koh YH, et al. Development of patient-derived preclinical platform for metastatic pancreatic cancer: PDOX and a subsequent organoid model system using percutaneous biopsy samples. Front Oncol. 2019:9:875.

19. Schreiber FS, Deramaudt TB, Brunner TB, Boretti MI, Gooch KJ, Stoffers DA, Bernhard EJ, Rustgi AK. Successful growth and characterization of mouse pancreatic ductal cells: functional properties of the KiRAS(G12V) oncogene. Gastroenterology. 2004:127(1):250-60.

20. Reichert M, Takano S, Heeg S, Bakir B, Botta GP, Rustgi AK. Isolation, culture and genetic manipulation of mouse pancreatic ductal cells. Nat Protoc. 2013;8(7):1354-65.

21. Lee KE, Bar-Sagi D. Oncogenic KRas suppresses inflammationassociated senescence of pancreatic ductal cells. Cancer Cell. 2010;18(5):448-58.

22. Tignanelli CJ, Herrera Loeza SG, Yeh JJ. KRAS and PIK3CA mutation frequencies in patient-derived xenograft models of pancreatic and colorectal cancer are reflective of patient tumors and stable across passages. Am Surg. 2014;80(9):873-7.

23. Greggio C, De Franceschi F, Fiqueiredo-Larsen M, Gobaa S, Ranga A, Semb H, Lutolf M, Grapin-Botton A. Artificial three-dimensional niches deconstruct pancreas development in vitro. Development. 2013;140(21):4452-62.

24. Agbunag C, Lee KE, Buontempo S, Bar-Sagi D. Pancreatic duct epithelial cell isolation and cultivation in two-dimensional and three-dimensional culture systems. Methods Enzymol. 2006;407:703-10.

25. Driehuis E, Gracanin A, Vries RGJ, Clevers H, Boj SF. Establishment of pancreatic organoids from normal tissue and tumors. STAR Protoc. 2020;1(3):100192.

26. Boj SF, Hwang Cl, Baker LA, Chio II, Engle DD, Corbo V, Jager M, PonzSarvise M, Tiriac H, Spector MS, et al. Organoid models of human and mouse ductal pancreatic cancer. Cell. 2015;160(1-2):324-38.

27. Huang L, Holtzinger A, Jagan I, BeGora M, Lohse I, Ngai N, Nostro C, Wang R, Muthuswamy LB, Crawford HC, et al. Ductal pancreatic cancer modeling and drug screening using human pluripotent stem cell- and patient-derived tumor organoids. Nat Med. 2015;21(11):1364-71.

28. Kim J, Hoffman JP, Alpaugh RK, Rhim AD, Reichert M, Stanger BZ, Furth EE, Sepulveda AR, Yuan CX, Won KJ, et al. An iPSC line from human 
pancreatic ductal adenocarcinoma undergoes early to invasive stages of pancreatic cancer progression. Cell Rep. 2013;3(6):2088-99.

29. Driehuis E, van Hoeck A, Moore K, Kolders S, Francies HE, Gulersonmez MC, Stigter ECA, Burgering B, Geurts V, Gracanin A, et al. Pancreatic cancer organoids recapitulate disease and allow personalized drug screening. Proc Natl Acad Sci USA. 2019;116:26580.

30. Tiriac H, Plenker D, Baker LA, Tuveson DA. Organoid models for translational pancreatic cancer research. Curr Opin Genet Dev. 2019;54:7-11.

31. Wedeken L, Luo A, Tremblay JR, Rawson J, Jin L, Gao D, Quijano J, Ku HT. Adult murine pancreatic progenitors require epidermal growth factor and nicotinamide for self-renewal and differentiation in a serum- and conditioned medium-free culture. Stem Cells Dev. 2017;26(8):599-607.

32. Broutier L, Andersson-Rolf A, Hindley CJ, Boj SF, Clevers H, Koo BK, Huch M. Culture and establishment of self-renewing human and mouse adult liver and pancreas 3D organoids and their genetic manipulation. Nat Protoc. 2016;1 1(9):1724-43.

33. Xu W, Yang XW, Zhao ZY, Dong B, Guan XY, Tian XY, Qian HG, Hao CY. Establishment of pancreatic cancer patient-derived xenograft models and comparison of the differences among the generations. Am J Transl Res. 2019;11(5):3128-39

34. Huch M, Bonfanti P, Boj SF, Sato T, Loomans CJ, van de Wetering M, Sojoodi M, Li VS, Schuijers J, Gracanin A, et al. Unlimited in vitro expansion of adult bi-potent pancreas progenitors through the Lgr5/R-spondin axis. EMBO J. 2013;32(20):2708-21.

35. Xu AT, Tong JL, Ran ZH. Organoids derived from digestive tract, liver, and pancreas. J Dig Dis. 2016;17(1):3-10.

36. Hohwieler M, Illing A, Hermann PC, Mayer T, Stockmann M, Perkhofer L, Eiseler T, Antony JS, Muller M, Renz S, et al. Human pluripotent stem cell-derived acinar/ductal organoids generate human pancreas upon orthotopic transplantation and allow disease modelling. Gut. 2017;66(3):473-86.

37. Lazzari G, Nicolas V, Matsusaki M, Akashi M, Couvreur P, Mura S. Multicellular spheroid based on a triple co-culture: a novel 3D model to mimic pancreatic tumor complexity. Acta Biomater. 2018;78:296-307.

38. Walsh AJ, Castellanos JA, Nagathihalli NS, Merchant NB, Skala MC. Optical imaging of drug-induced metabolism changes in murine and human pancreatic cancer organoids reveals heterogeneous drug response. Pancreas. 2016;45(6):863-9.

39. Boj SF, Hwang Cl, Baker LA, Engle DD, Tuveson DA, Clevers H. Model organoids provide new research opportunities for ductal pancreatic cancer. Mol Cell Oncol. 2016;3(1):e1014757.

40. Felsenstein M, Trujillo MA, Huang B, Nanda N, Jiang Z, Jeong YJ, Pfluger M, Goggins MG, Hruban RH, Thompson ED, et al. Generation and characterization of a cell line from an intraductal tubulopapillary neoplasm of the pancreas. Lab Invest. 2020;100(7):1003-13.

41. Broguiere N, Isenmann L, Hirt C, Ringel T, Placzek S, Cavalli E, Ringnalda F, Villiger L, Zullig R, Lehmann R, et al. Growth of epithelial organoids in a defined hydrogel. Adv Mater. 2018;30(43):e1801621.

42. Soltanian A, Ghezelayagh Z, Mazidi Z, Halvaei M, Mardpour S, Ashtiani MK, Hajizadeh-Saffar E, Tahamtani Y, Baharvand H. Generation of functional human pancreatic organoids by transplants of embryonic stem cell derivatives in a 3D-printed tissue trapper. J Cell Physiol. 2019:234(6):9564-76.

43. Vargas-Valderrama A, Messina A, Mitjavila-Garcia MT, Guenou H. The endothelium, a key actor in organ development and hPSC-derived organoid vascularization. J Biomed Sci. 2020;27(1):67.

44. Baker LA, Tiriac $H$, Tuveson DA. Generation and culture of human pancreatic ductal adenocarcinoma organoids from resected tumor specimens. Methods Mol Biol. 2019;1882:97-115.

45. Balak JRA, Juksar J, Carlotti F, Lo Nigro A, de Koning EJP. Organoids from the human fetal and adult pancreas. Curr Diab Rep. 2019;19(12):160.

46. Allaway RJ, Fischer DA, de Abreu FB, Gardner TB, Gordon SR, Barth RJ, Colacchio TA, Wood M, Kacsoh BZ, Bouley SJ, et al. Genomic characterization of patient-derived xenograft models established from fine needle aspirate biopsies of a primary pancreatic ductal adenocarcinoma and from patient-matched metastatic sites. Oncotarget. 2016;7(13):17087-102.

47. Moreira L, Bakir B, Chatterji P, Dantes Z, Reichert M, Rustgi AK. Pancreas 3D organoids: current and future aspects as a research platform for personalized medicine in pancreatic cancer. Cell Mol Gastroenterol Hepatol. 2018;5(3):289-98.
48. Filippini D, Agosto S, Delfino P, Simbolo M, Piro G, Rusev B, Veghini L, Cantu C, Lupo F, Ugel S, et al. Immunoevolution of mouse pancreatic organoid isografts from preinvasive to metastatic disease. Sci Rep. 2019;9(1):12286.

49. Lau AN, Li Z, Danai LV, Westermark AM, Darnell AM, Ferreira R, Gocheva V, Sivanand S, Lien EC, Sapp KM et al. Dissecting cell-type-specific metabolism in pancreatic ductal adenocarcinoma. Elife. 2020;9.

50. Russell J, Grkovski M, O'Donoghue IJ, Kalidindi TM, Pillarsetty N, Burnazi EM, Kulick A, Bahr A, Chang Q, LeKaye HC, et al. Predicting gemcitabine delivery by (18)F-FAC PET in murine models of pancreatic cancer. J Nucl Med. 2020;62:195-200.

51. Seino T, Kawasaki S, Shimokawa M, Tamagawa H, Toshimitsu K, Fujii M, Ohta Y, Matano M, Nanki K, Kawasaki K, et al. Human pancreatic tumor organoids reveal loss of stem cell niche factor dependence during disease progression. Cell Stem Cell. 2018;22(3):454-467e456.

52. Yoshida GJ. Applications of patient-derived tumor xenograft models and tumor organoids. J Hematol Oncol. 2020;13(1):4.

53. Weeber F, Ooft SN, Dijkstra KK, Voest EE. Tumor organoids as a pre-clinical cancer model for drug discovery. Cell Chem Biol. 2017;24(9):1092-100

54. Dossena M, Piras R, Cherubini A, Barilani M, Dugnani E, Salanitro F, Moreth T, Pampaloni F, Piemonti L, Lazzari L. Standardized GMP-compliant scalable production of human pancreas organoids. Stem Cell Res Ther. 2020;11(1):94.

55. Delitto D, Pham K, Vlada AC, Sarosi GA, Thomas RM, Behrns KE, Liu C, Hughes SJ, Wallet SM, Trevino JG. Patient-derived xenograft models for pancreatic adenocarcinoma demonstrate retention of tumor morphology through incorporation of murine stromal elements. Am J Pathol. 2015;185(5):1297-303.

56. Garcia PL, Miller AL, Yoon KJ. Patient-derived xenograft models of pancreatic cancer: overview and comparison with other types of models. Cancers (Basel). 2020;12(5):1327.

57. Georgakopoulos N, Prior N, Angres B, Mastrogiovanni G, Cagan A, Harrison D, Hindley CJ, Arnes-Benito R, Liau SS, Curd A, et al. Longterm expansion, genomic stability and in vivo safety of adult human pancreas organoids. BMC Dev Biol. 2020;20(1):4.

58. Hindley CJ, Cordero-Espinoza L, Huch M. Organoids from adult liver and pancreas: stem cell biology and biomedical utility. Dev Biol. 2016;420(2):251-61.

59. Lebreton F, Wassmer CH, Belofatto K, Berney T, Berishvili E. Insulinsecreting organoids: a first step towards the bioartificial pancreas. Med Sci (Paris). 2020;36(10):879-85.

60. Bartfeld S, Bayram T, van de Wetering M, Huch M, Begthel H, Kujala P, Vries R, Peters PJ, Clevers H. In vitro expansion of human gastric epithelial stem cells and their responses to bacterial infection. Gastroenterology. 2015;148(1):126-136e126.

61. Beato F, Reveron D, Dezsi KB, Ortiz A, Johnson JO, Chen DT, Ali K, Yoder $\mathrm{SJ}$, Jeong D, Malafa M, et al. Establishing a living biobank of patientderived organoids of intraductal papillary mucinous neoplasms of the pancreas. Lab Invest. 2020;18:688.

62. Chaudary N. Triplet CFTR modulators: future prospects for treatment of cystic fibrosis. Ther Clin Risk Manag. 2018;14:2375-83.

63. Clevers HC. Organoids: avatars for personalized medicine. Keio J Med. 2019;68(4):95

64. Koike H, Iwasawa K, Ouchi R, Maezawa M, Giesbrecht K, Saiki N, Ferguson A, Kimura M, Thompson WL, Wells JM, et al. Modelling human hepato-biliary-pancreatic organogenesis from the foregut-midgut boundary. Nature. 2019;574(7776):112-6.

65. Matsuzawa K, Akamatsu T, Katsuyama T. Mucin histochemistry of pancreatic duct cell carcinoma, with special reference to organoid differentiation simulating gastric pyloric mucosa. Hum Pathol. 1992;23(8):925-33.

66. Miyabayashi K, Baker LA, Deschenes A, Traub B, Caligiuri G, Plenker D, Alagesan B, Belleau P, Li S, Kendall J, et al. Intraductal transplantation models of human pancreatic ductal adenocarcinoma reveal progressive transition of molecular subtypes. Cancer Discov. 2020;10(10):1566-89.

67. Shibata W, Kinoshita H, Hikiba Y, Sato T, Ishii Y, Sue S, Sugimori M, Suzuki $\mathrm{N}$, Sakitani K, ljichi H, et al. Overexpression of HER2 in the pancreas promotes development of intraductal papillary mucinous neoplasms in mice. Sci Rep. 2018;8(1):6150. 
68. Nelson SR, Roche S, Cotter M, Garcia PA, Reitmeier D, Zollbrecht E, O'Neill F, Clynes M, Doolan P, Medha JP, et al. Genomic profiling and functional analysis of let-7c miRNA-mRNA interactions identify SOX13 to be involved in invasion and progression of pancreatic cancer. J Oncol. 2020;2020:2951921.

69. Boehnke K, Iversen PW, Schumacher D, Lallena MJ, Haro R, Amat J, Haybaeck J, Liebs S, Lange M, Schafer R, et al. Assay establishment and validation of a high-throughput screening platform for three-dimensional patient-derived colon cancer organoid cultures. J Biomol Screen. 2016;21(9):931-41.

70. Dantes Z, Yen HY, Pfarr N, Winter C, Steiger K, Muckenhuber A, Hennig A, Lange $S$, Engleitner T, Ollinger R et al. Implementing cell-free DNA of pancreatic cancer patient-derived organoids for personalized oncology. JCl Insight 2020;5(15).

71. Bishehsari F, Zhang L, Barlass U, Preite NZ, Turturro S, Najor MS, Shetuni BB, Zayas JP, Mahdavinia M, Abukhdeir AM, et al. KRAS mutation and epithelial-macrophage interplay in pancreatic neoplastic transformation. Int J Cancer. 2018;143(8):1994-2007.

72. Czernichow P, Reynaud K, Kerr-Conte J, Furthner E, Ravassard P. Production, characterization, and function of pseudoislets from perinatal canine pancreas. Cell Transplant. 2019;28(12):1641-51.

73. Dorrell C, Tarlow B, Wang Y, Canaday PS, Haft A, Schug J, Streeter PR, Finegold MJ, Shenje LT, Kaestner KH, et al. The organoid-initiating cells in mouse pancreas and liver are phenotypically and functionally similar. Stem Cell Res. 2014;13(2):275-83.

74. Braun LM, Lagies S, Klar RFU, Hussung S, Fritsch RM, Kammerer B, Wittel UA. metabolic profiling of early and late recurrent pancreatic ductal adenocarcinoma using patient-derived organoid cultures. Cancers (Basel). 2020;12(6):1440.

75. Heeg S, Das KK, Reichert M, Bakir B, Takano S, Caspers J, Aiello NM, Wu K, Neesse A, Maitra A, et al. ETS-transcription factor ETV1 regulates stromal expansion and metastasis in pancreatic cancer. Gastroenterology. 2016;151(3):540-553e514.

76. Hung YH, Sethupathy P. MicroRNAs in the mammalian gut endocrine lineage. Endocrinology. 2018;159(2):866-8.

77. Kaneta Y, Sato T, Hikiba Y, Sugimori M, Sue S, Kaneko H, Irie K, Sasaki $\mathrm{T}$, Kondo M, Chuma M, et al. Loss of pancreatic E-Cadherin causes pancreatitis-like changes and contributes to carcinogenesis. Cell Mol Gastroenterol Hepatol. 2020;9(1):105-19.

78. Lal S, Cheung EC, Zarei M, Preet R, Chand SN, Mambelli-Lisboa NC, Romeo C, Stout MC, Londin E, Goetz A, et al. CRISPR knockout of the HuR gene causes a xenograft lethal phenotype. Mol Cancer Res. 2017;15(6):696-707.

79. Loomans CJM, Williams Giuliani N, Balak J, Ringnalda F, van Gurp L, Huch M, Boj SF, Sato T, Kester L, de Sousa Lopes SMC, et al. Expansion of adult human pancreatic tissue yields organoids harboring progenitor cells with endocrine differentiation potential. Stem Cell Reports. 2018;10(3):712-24.

80. Mameishvili E, Serafimidis I, Iwaszkiewicz S, Lesche M, Reinhardt S, Bolicke N, Buttner M, Stellas D, Papadimitropoulou A, Szabolcs M, et al. Aldh1b1 expression defines progenitor cells in the adult pancreas and is required for Kras-induced pancreatic cancer. Proc Natl Acad Sci USA. 2019:116(41):20679-88.

81. Milligan DA, Tyler EJ, Bishop CL. Tissue engineering to better understand senescence: organotypics come of age. Mech Ageing Dev. 2020;190:111261.

82. Molnar R, Madacsy T, Varga A, Nemeth M, Katona X, Gorog M, Molnar B, Fanczal J, Rakonczay Z Jr, Hegyi P, et al. Mouse pancreatic ductal organoid culture as a relevant model to study exocrine pancreatic ion secretion. Lab Invest. 2020:100(1):84-97.

83. Petersen MBK, Goncalves CAC, Kim YH, Grapin-Botton A. Recapitulating and deciphering human pancreas development from human pluripotent stem cells in a dish. Curr Top Dev Biol. 2018;129:143-90.

84. Roe JS, Hwang Cl, Somerville TDD, Milazzo JP, Lee EJ, Da Silva B, Maiorino L, Tiriac H, Young CM, Miyabayashi K, et al. Enhancer reprogramming promotes pancreatic cancer metastasis. Cell. 2017;170(5):875-888e820.

85. Saito Y. Establishment of an organoid bank of biliary tract and pancreatic cancers and its application for personalized therapy and future treatment. J Gastroenterol Hepatol. 2019;34(11):1906-10.
86. Schwalie PC, Ordonez-Moran P, Huelsken J, Deplancke B. Crosstissue identification of somatic stem and progenitor cells using a single-cell RNA-sequencing derived gene signature. Stem Cells. 2017;35(12):2390-402.

87. Tremblay JR, Lopez K, Ku HT. A GLIS3-CD133-WNT-signaling axis regulates the self-renewal of adult murine pancreatic progenitor-like cells in colonies and organoids. J Biol Chem. 2019:294(45):16634-49.

88. Wang VM, Ferreira RMM, Almagro J, Evan T, Legrave N, Zaw Thin M, Frith D, Carvalho J, Barry DJ, Snijders AP, et al. CD9 identifies pancreatic cancer stem cells and modulates glutamine metabolism to fuel tumour growth. Nat Cell Biol. 2019;21(11):1425-35.

89. Yung T, Poon F, Liang M, Coquenlorge S, McGaugh EC, Hui CC, Wilson MD, Nostro MC, Kim TH. Sufu- and Spop-mediated downregulation of Hedgehog signaling promotes beta cell differentiation through organspecific niche signals. Nat Commun. 2019;10(1):4647.

90. Gendoo DMA, Denroche RE, Zhang A, Radulovich N, Jang GH, Lemire $M$, Fischer S, Chadwick D, Lungu IM, Ibrahimov $E$, et al. Whole genomes define concordance of matched primary, xenograft, and organoid models of pancreas cancer. PLoS Comput Biol. 2019;15(1):e1006596.

91. Huang B, Trujillo MA, Fujikura K, Qiu M, Chen F, Felsenstein M, Zhou C, Skaro M, Gauthier C, Macgregor-Das A, et al. Molecular characterization of organoids derived from pancreatic intraductal papillary mucinous neoplasms. J Pathol. 2020;252(3):252-62.

92. Burkhart RA, Baker LA, Tiriac H. Testing susceptibility of patient-derived organoid cultures to therapies: pharmacotyping. Methods Mol Biol. 2018;1787:253-61.

93. Pasch CA, Favreau PF, Yueh AE, Babiarz CP, Gillette AA, Sharick JT, Karim MR, Nickel KP, DeZeeuw AK, Sprackling CM, et al. Patient-derived cancer organoid cultures to predict sensitivity to chemotherapy and radiation. Clin Cancer Res. 2019;25(17):5376-87.

94. Aberle MR, Burkhart RA, Tiriac H, Olde Damink SWM, Dejong CHC, Tuveson DA, van Dam RM. Patient-derived organoid models help define personalized management of gastrointestinal cancer. Br J Surg. 2018;105(2)::48-60.

95. Tu MJ, Ho PY, Zhang QY, Jian C, Qiu JX, Kim EJ, Bold RJ, Gonzalez FJ, Bi H, Yu AM. Bioengineered miRNA-1291 prodrug therapy in pancreatic cancer cells and patient-derived xenograft mouse models. Cancer Lett. 2019:442:82-90.

96. Rauth S, Karmakar S, Batra SK, Ponnusamy MP. Recent advances in organoid development and applications in disease modeling. Biochim Biophys Acta Rev Cancer. 2021;1875(2):188527.

97. Russell J, Grkovski M, O'Donoghue IJ, Kalidindi TM, Pillarsetty N, Burnazi EM, Kulick A, Bahr A, Chang Q, LeKaye HC, et al. Predicting Gemcitabine Delivery by (18)F-FAC PET in Murine Models of Pancreatic Cancer. J Nucl Med. 2021;62(2):195-200

98. D'Agosto S, Andreani S, Scarpa A, Corbo V. Preclinical modelling of PDA: is organoid the new black? Int J Mol Sci. 2019;20(11):2766.

99. Ogoke $\mathrm{O}$, Maloy M, Parashurama N. The science and engineering of stem cell-derived organoids-examples from hepatic, biliary, and pancreatic tissues. Biol Rev Camb Philos Soc. 2020.

100. Inkoom A, Ndemazie N, Affram K, Smith T, Zhu X, Underwood P, Krishnan S, Ofori E, Han B, Trevino J, et al. Enhancing efficacy of gemcitabine in pancreatic patient-derived xenograft mouse models. Int J Pharm X. 2020;2:100056.

101. Kawaguchi K, Han Q, Li S, Tan Y, Igarashi K, Miyake K, Kiyuna T, Miyake M, Chemielwski B, Nelson SD, et al. Intra-tumor L-methionine level highly correlates with tumor size in both pancreatic cancer and melanoma patient-derived orthotopic xenograft (PDOX) nude-mouse models. Oncotarget. 2018;9(13):11119-25.

102. Kawaguchi K, Miyake K, Zhao M, Kiyuna T, Igarashi K, Miyake M, Higuchi T, Oshiro H, Bouvet M, Unno M, et al. Tumor targeting Salmonella typhimurium A1-R in combination with gemcitabine (GEM) regresses partially GEM-resistant pancreatic cancer patient-derived orthotopic xenograft (PDOX) nude mouse models. Cell Cycle. 2018;17(16):2019-26.

103. Liu Z, Ahn MH, Kurokawa T, Ly A, Zhang G, Wang F, Yamada T, Sadagopan $A$, Cheng J, Ferrone CR, et al. A fast, simple, and cost-effective method of expanding patient-derived xenograft mouse models of pancreatic ductal adenocarcinoma. J Transl Med. 2020;18(1):255.

104. Mattie M, Christensen A, Chang MS, Yeh W, Said S, Shostak Y, Capo L, Verlinsky A, An Z, Joseph I, et al. Molecular characterization of patientderived human pancreatic tumor xenograft models for preclinical 
and translational development of cancer therapeutics. Neoplasia. 2013;15(10):1138-50.

105. Broekgaarden M, Anbil S, Bulin AL, Obaid G, Mai Z, Baglo Y, Rizvi I, Hasan T. Modulation of redox metabolism negates cancer-associated fibroblasts-induced treatment resistance in a heterotypic 3D culture platform of pancreatic cancer. Biomaterials. 2019;222:119421.

106. Brevini TAL, Manzoni EFM, Ledda S, Gandolf F. Use of a super-hydrophobic microbioreactor to generate and boost pancreatic mini-organoids. Methods Mol Biol. 2019:1576:291-9.

107. Dayem AA, Lee SB, Kim K, Lim KM, Jeon TI, Cho SG. Recent advances in organoid culture for insulin production and diabetes therapy: methods and challenges. BMB Rep. 2019;52(5):295-303.

108. Genova E, Cavion F, Lucafo M, Leo L, Pelin M, Stocco G, Decorti G. Induced pluripotent stem cells for therapy personalization in pediatric patients: focus on drug-induced adverse events. World J Stem Cells. 2019:11(12):1020-44.
109. Gu ZY, Jia SZ, Liu S, Leng JH. Endometrial organoids: a new model for the research of endometrial related diseasesdagger. Biol Reprod. 2020;103:918.

110. Manzar GS, Kim EM, Zavazava N. Demethylation of induced pluripotent stem cells from type 1 diabetic patients enhances differentiation into functional pancreatic beta cells. J Biol Chem. 2017;292(34):14066-79.

111. Vives J, Batlle-Morera L. The challenge of developing human 3D organoids into medicines. Stem Cell Res Ther. 2020;11(1):72.

\section{Publisher's Note}

Springer Nature remains neutral with regard to jurisdictional claims in published maps and institutional affiliations.
Ready to submit your research? Choose BMC and benefit from:

- fast, convenient online submission

- thorough peer review by experienced researchers in your field

- rapid publication on acceptance

- support for research data, including large and complex data types

- gold Open Access which fosters wider collaboration and increased citations

- maximum visibility for your research: over $100 \mathrm{M}$ website views per year

At BMC, research is always in progress.

Learn more biomedcentral.com/submissions 